\title{
Optimization of an atmospheric air volumetric central receiver system: Impact of solar multiple, storage capacity and control strategy
}

\author{
Bruno Coelho ${ }^{a},{ }^{*}$, Szabolcs Varga ${ }^{a}$, Armando Oliveira $^{a}$, Adélio Mendes ${ }^{b}$ \\ a New Energy Technologies Research Unit, IdMEC e Institute of Mechanical Engineering, \\ University of Porto, Faculty of Engineering, Rua Roberto Frias, 4200-465 Porto, Portugal \\ b Laboratory for Process, Environmental and Energy Engineering (LEPAE), University of Porto, \\ Faculty of Engineering, Rua Roberto Frias, 4200-465 Porto, Portugal
}

\begin{abstract}
Portugal has a high potential for concentrated solar power and namely for atmospheric air volumetric central receiver systems (CRS). The solar multiple and storage capacity have a significant impact on the power plant levelized electricity cost (LEC) and their optimization and adequate control strategy can save significant capital for the investors. The optimized proposed volumetric central receiver system showed good performance and economical indicators.

For Faro conditions, the best $4 \mathrm{MWe}$ power plant configuration was obtained for a 1.25 solar multiple and a $2 \mathrm{~h}$ storage. Applying control strategy \#1 (CS\#1) the power plant LEC is 0.234 $€ / \mathrm{kWh}$ with a capital investment (CAPEX) of $€ 22.3$ million. The capital invested has an internal rate of return (IRR) of $9.8 \%$, with a payback time of 14 years and a net present value (NPV) of $€$ 7.9 million (considering an average annual inflation of $4 \%$ ). In the case of better economical indicators, the power plant investment can have positive contours, with an NPV close to $€ 13$ million (annual average inflation of $2 \%$ ) and the payback shortened to 13 years.
\end{abstract}




\begin{tabular}{|c|c|c|c|}
\hline \multicolumn{2}{|c|}{ Nomenclature } & HRSG & heat recovery steam generator \\
\hline & & HTF & heat transfer fluid \\
\hline$\alpha$ & escalation factor & IC & indirect costs \\
\hline CAPEX & capital investment & IRR & internal rate of return \\
\hline \multirow[t]{2}{*}{$C_{\mathrm{E}, \mathrm{W}}$} & cost of the reference equipment at reference size or & $K_{\text {fuel }}$ & annual fuel costs \\
\hline & capacity & $K_{08 \mathrm{M}}$ & annual operation and maintenance costs \\
\hline$C_{E, Y}$ & cost of equipment at the required size or capacity & $\mathrm{kW}_{\mathrm{e}}$ & kilowatt electric \\
\hline$C_{\text {If }}$ & insurance and debt interest coefficient rate & $\mathrm{kW}_{\text {th }}$ & kilowatt thermal \\
\hline CRS & central receiver system & LEC & levelized electricity cost \\
\hline \multirow{4}{*}{\multicolumn{2}{|c|}{$\begin{array}{l}\text { CRS_SM\#_\#S_CS\# central receiver power plant with (\# } \\
\text { multiple) of solar multiple, (\# equivalent } \\
\text { hours) of storage capacity and applying } \\
\text { control strategy (\# CS) }\end{array}$}} & $\mathrm{MW}_{\mathrm{e}}$ & megawatt electric \\
\hline & & NPV & net present value \\
\hline & & $Q_{\mathrm{DNI}}$ & power intercepted by the solar field \\
\hline & & $Q_{\mathrm{Int}}$ & receiver intercept power \\
\hline CS & control strategy & $Q_{D}$ & power dumping \\
\hline CSP & concentrated solar power & $Q_{\mathrm{PB}}$ & power input to power block \\
\hline DC & direct costs & $Q_{\text {Rec }}$ & receiver output power \\
\hline DLR & Deutsches Zentrum für Luft- und Raumfahrt & $Q_{s}$ & power to/from storage \\
\hline DNI & direct normal irradiation & REN & Portuguese electricity network, managed by the \\
\hline DP & design point & & company REN (Rede Eléctrica Nacional) \\
\hline EBSILON & Ebsilon Professional software & SM & solar multiple \\
\hline ECOSTAR & European concentrated solar thermal road-mapping & $S_{\max }$ & storage maximum \\
\hline$E_{\text {gross }}$ & gross generated electricity & TES & thermal energy storage \\
\hline & net generated electricity & UPORTO & Universidade do Porto \\
\hline & energy stored & $X_{\mathrm{W}}$ & size or capacity of the reference equipment \\
\hline HFLCAL & Heliostat Field Layout CALculation & $X_{y}$ & size or capacity of the required equipment \\
\hline
\end{tabular}

\section{Introduction}

\subsection{Local context}

Currently there are four concentrating solar power technologies (CSPs) applied in commercial power plants: central receiver systems (CRSs), parabolic trough, linear Fresnel and dish-Stirling engine. The South of Portugal is one of the European regions with higher annual solar direct normal irradiation (DNI). With the objective of exploring this potential, Portuguese authorities launched a recent call for network integration [1] of several small-scale projects (up to $4 \mathrm{MWe}$ ) with the objective of building a CSP cluster using four commercial different CSP technologies. The CRS winner project was a 4 MWe atmospheric air volumetric CRS. This is one of the most promising CSP technologies; it uses a field of two-axis tracking mirrors (heliostats) to concentrate solar direct normal irradiation (DNI), with concentration factors above 1000, into a solar receiver, exchanging heat with a heat transfer fluid (HTF) that drives the power block with good operating performances [2]. CRS power plants can be sub-divided according to the HTF: steam, atmospheric air, pressurized air and molten salts. Comparing all HTFs, atmospheric air has advantages in terms of availability, cost and environmental impact. Atmospheric air can be heated in a volumetric receiver, using concentrated solar energy, to temperatures around $700{ }^{\circ} \mathrm{C}$, generating steam at $480-540{ }^{\circ} \mathrm{C}$ and $35-140$ bar in a heat recovery steam generator (HRSG), which feeds a steam tur-bine paired with an electricity generator [2]. The most common power cycle used in commercial CSP power plants is the Rankine cycle, but other cycles such as the organic Rankine cycle or Brayton cycle (in pressurized air receivers) can also be used. Typically, the storage device is used to guarantee the power generation stability and/or extend operation, storing heat for several hours, which can be loaded or unloaded by reversing the airflow with two axial blowers, Fig. 1. The state of the art of atmospheric air volumetric CRS is Jülich solar tower (solar multiple 1.2, storage capacity of 1 nominal hour and steam conditions of 27 bar and $485^{\circ} \mathrm{C}$ ) [3]. 


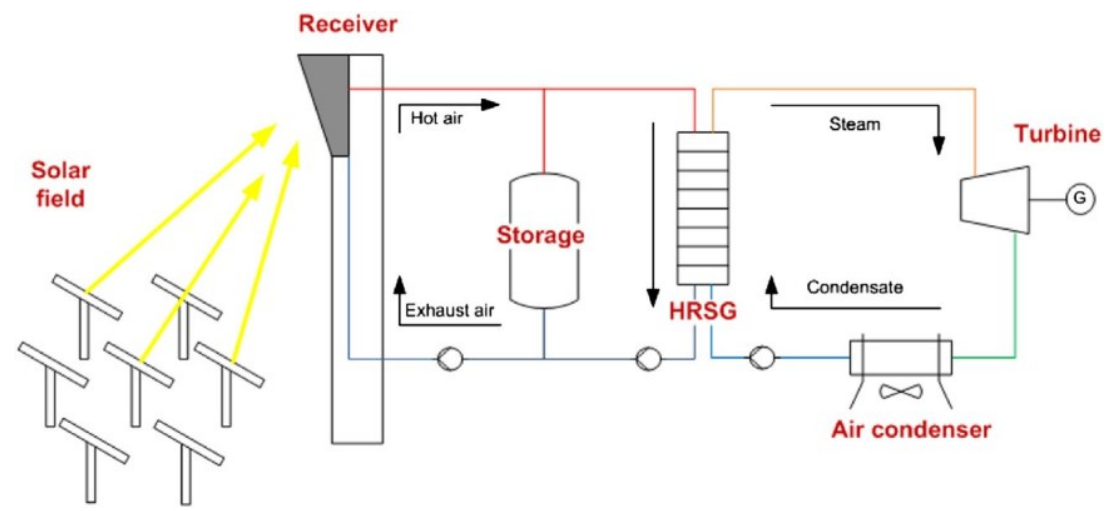

Fig. 1. Atmospheric air volumetric CRS schematic.

\subsection{Solar multiple}

Power plant design is carried out from downstream to up-stream: starting with the licensed power definition, steam cycle, air cycle, receiver and solar field. External limitations, such as available land and topography, affect power plant design. These limitations must be respected in power plant design and optimization processes. Several factors affect this phase, e.g. the solar multiple, storage capacity and control strategy, influencing power plant performance and cost, and their optimization is essential to find the best power plant design. The solar multiple (SM) is the ratio between the thermal power generated by the collector system (solar field and receiver) at the design point (DP) and the thermal power required by the power block at nominal conditions, Equation (1).

$$
\mathrm{SM}_{\mathrm{DP}}=\frac{Q_{\mathrm{Rec}, \mathrm{DP}}}{Q_{\mathrm{PB}, \mathrm{DP}}}
$$

The solar multiple defines the solar field excess power above the nominal power necessary to run the power block and which, in most cases, is stored or otherwise wasted. In solar-only power plants the solar multiple is always greater than one, so the power block operation is not confined only to solar clear sky conditions. The increase in solar multiple also represents higher capital investment (CAPEX), larger solar field, land area and receiver costs. Also the increase of solar multiple represents an increase in the solar field intercept power, Fig. 2. 


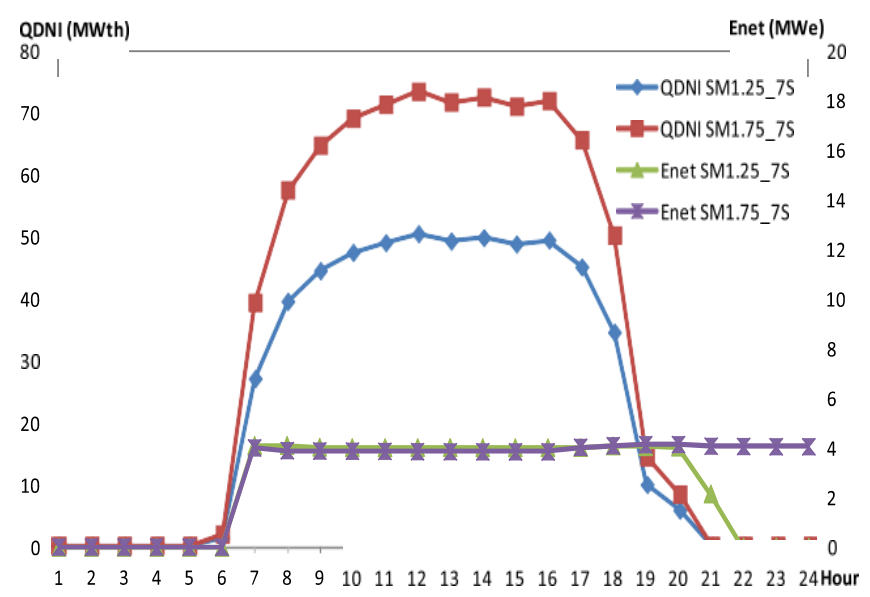

Fig. 2. Typical summer day history of available power from the solar field and generated electricity as a function of different solar multiples (lines are for readability).

\subsection{Thermal energy storage}

The power plant with 1.75 solar multiple (SM1.75_7S, Fig. 2) collects more solar energy than the power plant with solar multiple of 1.25 (SM1.25_7S, Fig. 2) and, as a result, the period of power block full load operation is extended. This is only possible using thermal energy storage (TES); otherwise this energy is dumped. With TES it is possible to decouple the power generation from the solar resource. Electricity generation can occur without solar resource and/or on demand by the electricity network, Fig. 2. The storage unit confers this essential and unique dispatchability characteristic to CSP electricity generation. It is thus possible to adapt the electricity generation profile to the national electricity demand, decreasing the need of backup and stand-by power. The Portuguese electricity consumption during a typical summer day is presented on Fig. 3.

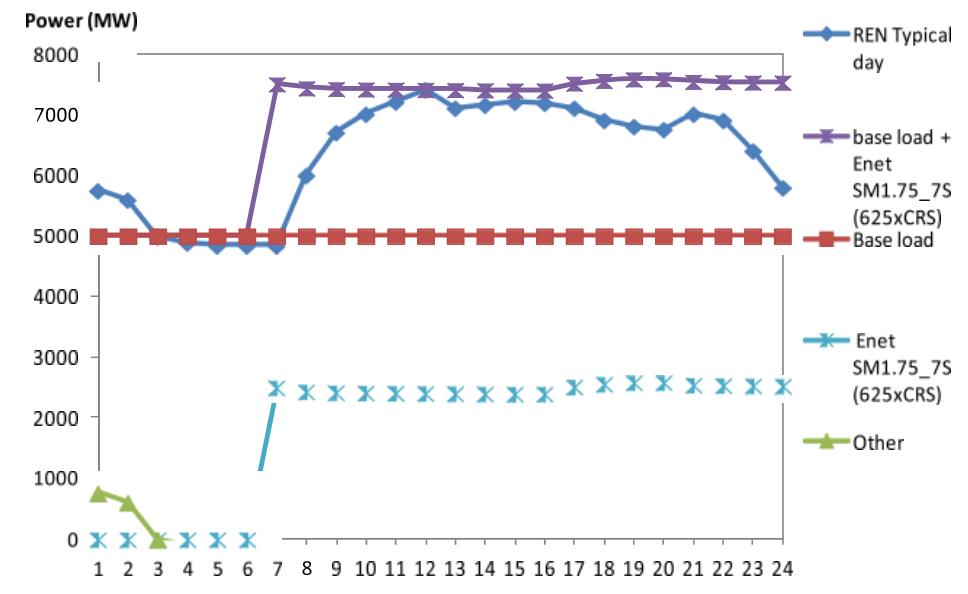

Fig. 3. Scenario for CSP potential and Portuguese electricity consumption e REN typical day [4] (lines are for readability). 
A possible way to supply the electricity demand with CSP is by using large thermal energy storage that allows operating almost on a 24-h daily base, Fig. 3. As this is a costly solution, an alternative is to use the CSP hybridization potential [5]. Using only CSP it is possible to respond to the Portuguese network consumption day peak (7:00 to 24:00) with 625 CRSs (4 MWe each with SM of 1.75 and $7 \mathrm{~h}$ storage), generating 10.2 TWh of electricity per year. This is far from the 142 TWh economic potential referred by the MED-CSP study [6] for CSP power plants in Portugal. Although this scenario in not probable to occur in the short term, CSP technologies can provide base load power, either in solar only mode or in more cost efficient hybrid solutions. Even in these hybrid solutions the storage unit confers stability and reliability to the electricity generation, preventing component failure and improving power plant performance.

Thermal energy storage can be divided into two groups: sensible heat storage systems and latent storage systems [7]. In sensible heat storage systems the storage device releases or absorbs energy from a fluid, changing the storage temperature and maintaining its physical state. When there is a phase change, from solid into a liquid, or from liquid into a gas, the heat released or stored is called heat of fusion (solid to liquid) or heat of vaporization (liquid to gas). Both are commonly referred as latent heat and differ from sensible heat, as there is no temperature change associated. Another perspective of heat storage is to use reversible chemical reactions which use heat for progressing in either direction. TES can also be classified considering the type and utilization. TES can be used for short-term operation (providing operational short-term stability) or medium/long term (increasing the power plant capacity factor and allow to decouple the electricity generation period from the solar collection period). TES types can also be divided into active direct storage (the HTF is the same as the TES fluid e does not require additional heat exchangers), active indirect storage (different HTF using a heat exchanger) and passive storage (e.g. by heating a solid material such as concrete or ceramics) [7]. All these TES systems operate using three steps: charging, storing and discharging.

In the case of atmospheric air volumetric CRS the HTF is atmospheric air, and, because air has very low energy density and conductivity, direct active heat storage is not a good solution. The technology applied in the Jülich solar tower is a regenerator-type storage (passive storage) where a gaseous heat transfer fluid is in direct contact with a solid storage medium and exchanges heat as it flows along a path through the storage medium [8]. The storage device is a rectangular housing of $7 \times 7 \times 6 \mathrm{~m}^{3}$ (total volume of $120 \mathrm{~m}^{3}$ ), divided into four chambers of identical size, filled with a ceramic storage material, and connected in parallel. The storage system operates between 120 and $680^{\circ} \mathrm{C}$ and has a capacity of almost $9 \mathrm{MWh}$. The total heat loss in a $24 \mathrm{~h}$ period is $930 \mathrm{kWh}$ with a pressure drop of $15 \mathrm{mbar}$ [8]. There are some limitations on the number of equivalent hours of storage (between 3 and $6 \mathrm{~h}$ ), due to technological and economical reasons [9].

\subsection{Control strategy}

The optimal storage size depends on the solar multiple and control strategy. The control strategy is the power plant operational strategy and varies during the day e.g. according to network 
especial needs, contract to the electricity purchase entity, feed-in tariff, technologies used in the power plant and staff available. Several countries have premium feed-in electricity tariffs for pro-ducers during the day while others have fixed feed-in tariffs or forecast obligations [10]. In the Portuguese case the power plant operator can choose if he wants to receive the same remuneration regardless of the time of the day, or a higher tariff for electricity generated during the day than during the night. In the last case, the amount of electricity generated between 8:00 and 22:00 during wintertime and 9:00 and 23:00 during summertime is multiplied by 1.25 and the rest of the electricity is multiplied by 0.6 [10]. As the feed-in tariff calculation formula is complex, the regulators release the value for each project or call; in the case of the latest CSP call, the feed-in tariff is $0.273 € / \mathrm{kWh}$.

\section{CRS model}

\subsection{Power plant designs}

The process to find the optimal solar plant depends on several variables and is highly iterative as all variables are interdependent and consequently their optimization involves the entire solar power plant. The start case for this study was a $4 \mathrm{MWe}$ atmospheric air volumetric CRS that generates, at nominal conditions, steam at $480{ }^{\circ} \mathrm{C}$ and 80 bar. The heliostat dimensions and tower height were respectively $60 \mathrm{~m}^{2}$ and $97 \mathrm{~m}$. Solar fluxes into the receiver were kept within the $550 \mathrm{~kW} / \mathrm{m}^{2}$ average design flux with a maximum peak solar flux of $950 \mathrm{~kW} / \mathrm{m}^{2}$. Several options were analysed to find the best solar multiple, storage capacity and control strategy. For each option (set of solar multiple/storage capacity/control strategy), different receivers and blowers were simulated. The tested sets of solar multiple/storage capacities were:

- Solar multiples of $1 ; 1.25 ; 1.5 ; 1.75 ; 2$;

- Storage capacities of $1 ; 2 ; 3 ; 4 ; 5 ; 6$ equivalent hours for each solar multiple.

For each solar multiple a different solar field configuration and layout was optimized using HFLCAL. As for higher solar multiples larger intercept power and solar field are necessary, two alternatives were considered: a different distribution of the heliostats focal points in the receiver or, if it is insufficient, the receiver area was increased. For the design DNI of $750 \mathrm{~W} / \mathrm{m} 2$ the receiver dimensions obtained were:

- Solar multiple of 1 - receiver area of $48.6 \mathrm{~m}^{2}$;

- Solar multiple of 1.25 - receiver area of $60.0 \mathrm{~m}^{2}$;

- Solar multiple of 1.5 - receiver area of $72.6 \mathrm{~m}^{2}$;

- Solar multiple of 1.75 - receiver area of $85.0 \mathrm{~m}^{2}$;

- Solar multiple of 2 - receiver area of $96.8 \mathrm{~m}^{2}$.

\subsection{Operation strategies}

Solar multiple and storage capacity are important design variables in the CRS optimization process. Their optimization is also dependent on the operational strategy, selected by the power plant responsible. For CRS power plants with large storage devices (or hybrid), a larger staff team is needed for ca. $24 \mathrm{~h}$ daily operation, while power plants with smaller storage devices need a small staff team. But it is only possible to find the best control strategy for a specific CRS via an 
optimization process, involving the thermal storage capacity, solar multiple, energy dumping, feed-in tariff or the need to generate power on demand. Four different control strategies were considered:

- Control strategy \#1 (CS\#1) e it is the most common control strategy in commercial CRS; it uses the solar power to run the power block and the excess heat is stored. This stored energy is used to cover solar transients and extend operation until storage is empty. The staff is escalated for 2 shifts with extra-hours for extended operation.

In CS\#1, during power plant start-up, there is a period of time when solar radiation is not enough to run the power block and begin generating electricity (CS\#1, n? 1 , Fig. 4). This period is dependent on the inertia of components and on the available solar radiation. To minimize this start-up period, a different control strategy can be used taking advantage of residual energy stored from the previous day. Another alternative to reduce this start-up period and avoid transient problems is the integration of a fuel burner (full or partial hybridization). After startup, the power block begins generating electricity, and, because the power plant is designed for solar multiples higher than 1 , heat from the solar receiver surpasses the needs from the power block. During this period (CS\#1, no3, Fig. 4), the energy excess is stored while the power block is generating electricity at nominal power. When the storage device maximum capacity is reached, the excess energy is dumped, normally by defocusing heliostats from the receiver. In the evening (CS\#1, n5, Fig. 4), the axial blowers reverse the flow and use the energy stored to compensate the solar radiation scarcity, extending power plant operation until the storage is empty. The decision diagram for CS\#1 is based on C.J. Winter decision diagram [11], Fig. 5.

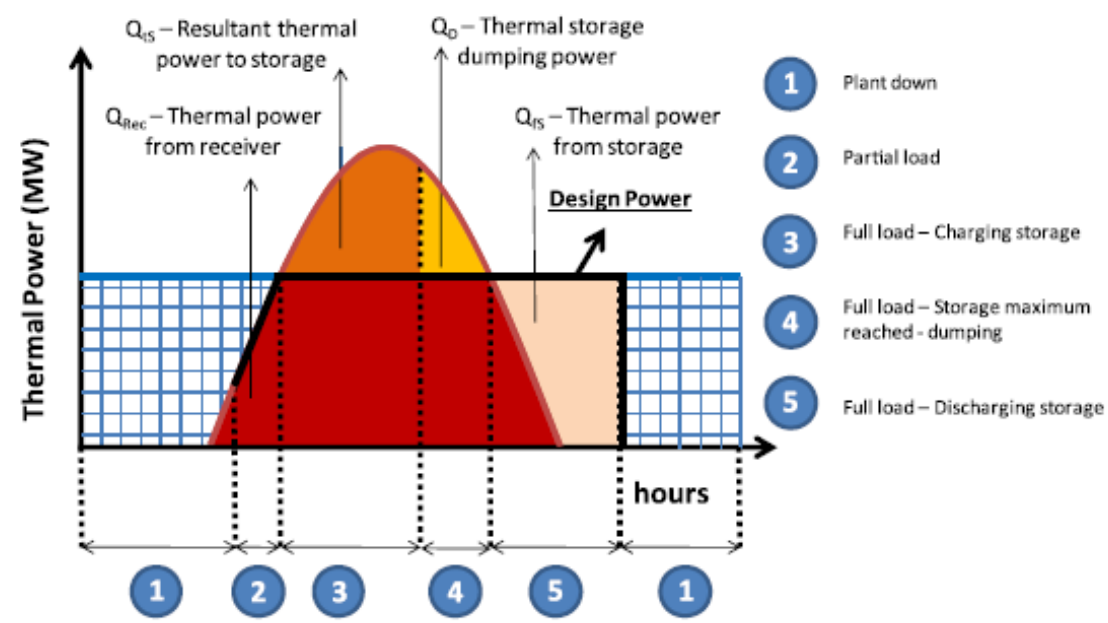

Fig. 4. Application of control strategy to a typical operating day with CS\#1 


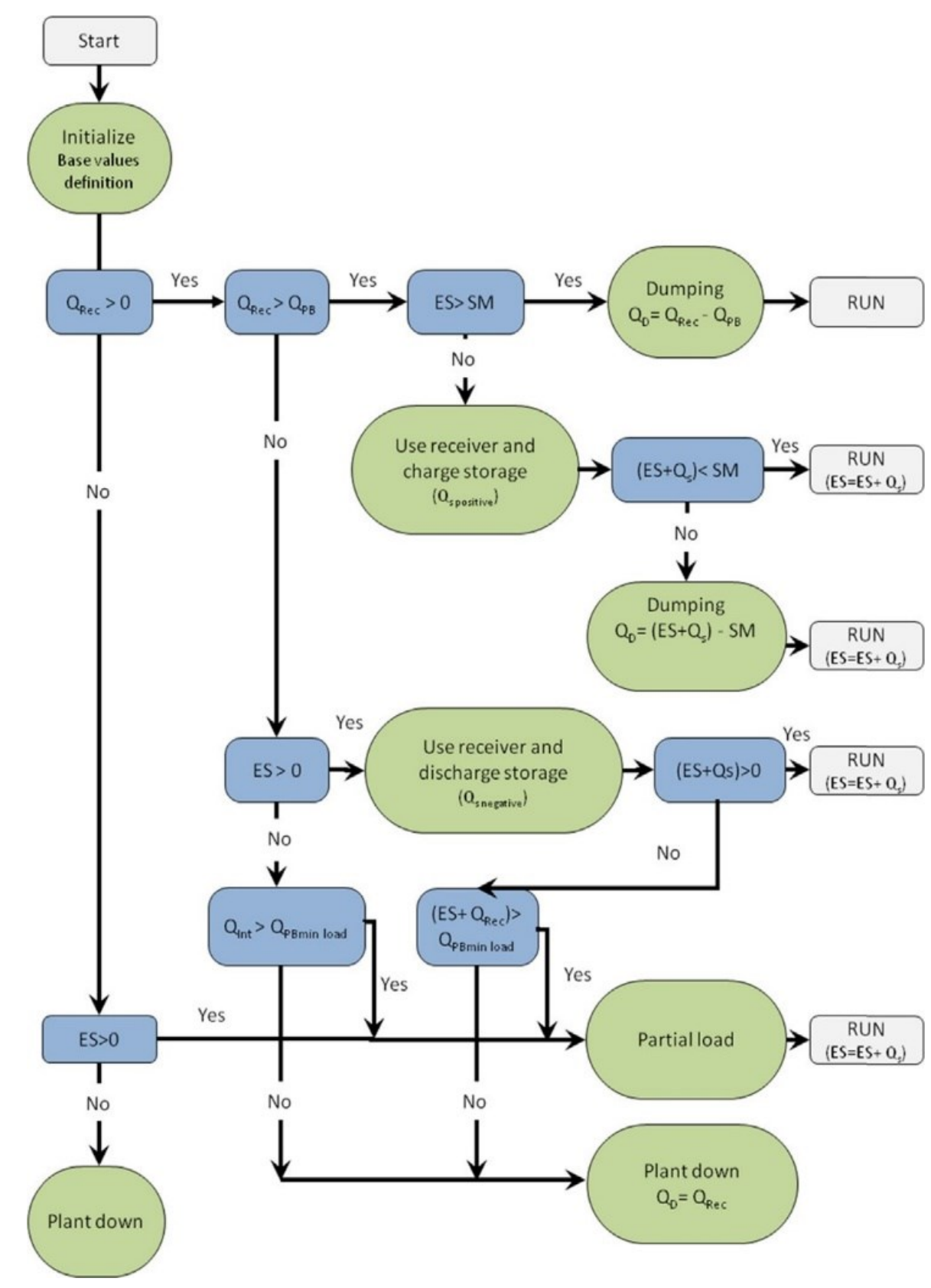

Fig. 5. Decision diagram for CS\#1 control strategy on a CRS.

The other control strategies considered are control strategy \#2 (CS\#2), with the power plant operating only in two fixed shifts (6:00 to $22: 00)$ and the remaining energy being stored for the next day start-up, and control strategy \#3 (CS\#3) with the power plant operating only in one shift and reduced personnel costs:

- Control strategy \#2 (CS\#2) e power plant operates during 2 shifts without extra hours (6:00 to $22: 00 \mathrm{~h}$ ), storing any excess heat for power plant start-up in the next day;

- Control strategy \#3 (CS\#3) e power plant operates during 1 shift (8:00 to 16:00 h) plus 2 extra hour operation when necessary (16:00 to 18:00), storing any excess heat for power plant start-up in the next day; 
The aim of control strategies \#1, \#2 and \#3 is to use of CRS for base load power, with the power plant generating an almost continuous electricity flow to the grid. However, 24-h operation of an atmospheric air volumetric CRS is not common, due to the thermal storage cost and size. A different perspective for CRS power plants is to generate power on demand, mainly to support the peak electricity consumption periods with bonus feed-in tariffs. Fig. 3 shows the electricity consumption in Portugal for a typical summer day, with consumption peaks from 9:00 to 13:00 and 18:00 to $21: 00$ (these peaks are even more pronounced during the winter). CSP can also be used to cope with this demand defining a control strategy for these conditions:

- Control strategy \#4 (CS\#4) e the power plant operates at nominal load (4 MWe) only during hours with high network electricity demand (9:00 to 13:00 and 18:00 to 22:00) and at minimum power block load ( $2 \mathrm{MWe}$ ) during the remaining period.

The models developed for this work were solved using different tools. HFLCAL [12] was used for solar field optimization, EBSILON [13] was used for power block optimization and Excel was used for results compilation and economical evaluation. For each option the air cycle was designed and optimized using Ebsilon Professional, while the solar field was designed and optimized using HFLCAL. The power plant economics were calculated using Excel; for each time step, Excel was used as an interface for running EBSILON. The software interconnections are presented in Fig. 6.

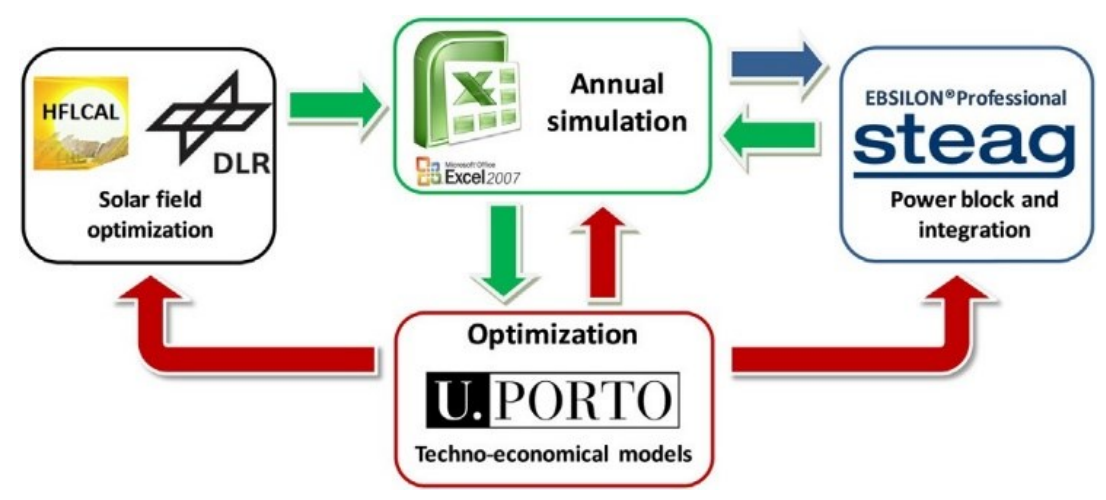

Fig. 6. Tools used for power plant design and annual simulation.

\subsection{Economical considerations}

The decision to invest in CRS power plants is based on economical indicators. An economical model was developed for obtaining complete impact analysis of different power plant configurations. The costs for the base case are given in Table 1:

Table 1. Economic model for the $4 \mathrm{MWe}$ CRS base case. 


\begin{tabular}{ll}
\hline & UPORTO model $-4 \mathrm{MW}$ unit at Faro - base case \\
\hline Direct costs (DC) & $150 € / \mathrm{m}^{2}$ \\
Solar field & $120 € / \mathrm{kW}_{\text {th }}[14]$ \\
Receiver & $1,000,000 €[15]$ \\
Tower & $64 € / \mathrm{kWh}^{-}$ \\
Storage & $670 € / \mathrm{kW}_{\mathrm{e}}[14]$ \\
Power block & $3.6 € / \mathrm{m}^{2}[15]$ \\
Land & $20 \%$ of DC \\
Indirect costs (IC) & \\
\hline
\end{tabular}

The solar field cost was calculated according to the Helio3s design from UPORTO and lies within commercial range [16]. A cost model was developed for the solar receiver (based on receiver power and dimensions) and power block (based on components design and operating conditions) [14], cf. Table 1. The storage device cost was based on ECOSTAR report [9] using an escalation factor of 0.93 , according to Equation (2):

$$
C_{\mathrm{E}, \mathrm{Y}}=C_{\mathrm{E}, \mathrm{W}}\left(\frac{X_{\mathrm{Y}}}{X_{\mathrm{W}}}\right)^{a}
$$

where $C_{E, Y}$ is the cost of equipment at the required size or capacity, $C_{E, W}$ is the cost of the reference equipment at reference size or capacity, $X_{Y}$ is the size or capacity of the required equipment, $X_{W}$ is the size or capacity of the reference equipment and $\alpha$ is the escalation factor. The price of the different CRS configurations was analysed using Equation (2). The escalation factors considered were based on ECOSTAR report [9] (solar field e 0.95; receiver e 0.87; storage e 0.93).

Table 1 was validated with data from manufacturers [17] and reliable references $[9,18,19]$. The tower and land costs were checked locally with and supply companies [15]. The indirect costs were estimated based on Guthrie's method [18] and the power plant LEC was calculated according to the IEA method [9]. LEC is dependent on the power plant capital investment (CAPEX), debt interests and insurance rates, annual operation and maintenance costs, annual fuel costs, depreciation time and generated annual net electricity, according to Equation (3).

$$
L E C=\frac{C_{\mathrm{rf}} \cdot C A P E X+K_{\mathrm{O} \& \mathrm{M}}+K_{\mathrm{fuel}}}{E_{\text {net }}}
$$

where $\mathrm{C}_{\mathrm{rf}}$ is the insurance and debt interest coefficient rate, CAPEX is the total capital investment for the power plant, $\mathrm{K}_{\text {o\&m }}$ is the annual operation and maintenance costs, $\mathrm{K}_{\text {fuel }}$ is the annual fuel cost and, $E_{n e t}$ is the annual net electricity.

A more comprehensive economical model was built, calculating the cash flows and finding the investment return rate and period. This project cash flow analysis is dependent on financial factors (fraction of own capital used, amortization structure, debt payment structure and methods used for future cash flow calculation) and power plant technical factors (power degradation, equipments performance and cost). The estimations considered for the cash flow analysis were: a $30 \%$ own capital, a 20 -year loan with an interest rate of $8 \%$, a $1 \%$ annual insurance rate, a linear amortization for 20 years, current national profit taxes and a $1 \%$ of power 
degradation. Both economical models (LEC and cash flows) results were subject of a sensitivity analysis to determine the impact of variations in the parameters estimative.

\section{Results and discussion}

The design and performance of the solar field were obtained with HFLCAL and the receiver performance was modelled using DLR receiver experimental data. Storage off-design performance was approximated by a constant loss factor and the power block design and performance was based on data from manufacturers using EBSILON characteristic lines for offdesign operation. Table 2 presents the main design conditions for the different solar multiple designs and $4 \mathrm{MWe}$ nominal power operating under Portuguese weather conditions.

Table 2. CRA design conditions for the different solar multiples

\begin{tabular}{|c|c|c|c|c|}
\hline & SM 1.25 & SM 1.5 & SM 1.75 & SM 2.0 \\
\hline \multicolumn{5}{|l|}{ Solar field } \\
\hline Heliostat reflective area $\left(\mathrm{m}^{2}\right)$ & 60 & 60 & 60 & 60 \\
\hline Field density (\%) & 18 & 16 & 15 & 14 \\
\hline Total mirror area $\left(\mathrm{m}^{2}\right)$ & 53,580 & 65,760 & 78,060 & 91,020 \\
\hline Land area (hec) & 21 & 26 & 31 & 36 \\
\hline \multicolumn{5}{|l|}{ Receiver } \\
\hline Area $\left(\mathrm{m}^{2}\right)$ & 60 & 73 & 85 & 97 \\
\hline Design power (MW) & 24 & 29 & 33 & 38 \\
\hline \multicolumn{5}{|l|}{ Storage } \\
\hline Capacity nominal hours (hour) & 2 & 2 & 2 & 2 \\
\hline Capacity power (MWh) & 34 & 34 & 34 & 34 \\
\hline \multicolumn{5}{|l|}{ Power block } \\
\hline Electric power gross (MW) & 4.6 & 4.6 & 4.6 & 4.6 \\
\hline Electric power net (MW) & 4.0 & 4.0 & 4.0 & 4.0 \\
\hline
\end{tabular}

The receiver design power increases for higher solar multiples; though higher solar multiples need more heliostats. The location of these supplementary heliostats is farer from the receiver and, due to higher blocking and shading losses their distribution is more spaced, resulting in lower field densities, Table 2, which affects the solar field efficiency, Fig. 7.

As shown in Fig. 7 (central area), for higher solar multiples the number of solar positions with good solar efficiencies is reduced, and so the annual solar field efficiency is lower. Also, the increase in solar multiple corresponds to a power plant CAPEX increase, due to a significant higher solar field area and receiver power and dimensions, Table 3.

Table 3. Cost distribution for power plants with different SM 


\begin{tabular}{lcccc}
\hline & SM 1.25 & SM 1.5 & SM 1.75 & SM 2.0 \\
\hline Direct costs (million $€$ ) & & & & \\
Solar field & 8.0 & 9.8 & 11.5 & 13.3 \\
Receiver & 3.5 & 4.1 & 4.7 & 5.2 \\
Tower & 1.0 & 1.0 & 1.0 & 1.0 \\
Storage & 2.2 & 2.2 & 2.2 & 2.2 \\
Power block & 3.1 & 3.1 & 3.1 & 3.1 \\
Land & 0.8 & 0.9 & 1.1 & 1.3 \\
Indirect costs (million $€$ ) & 3.7 & 4.1 & 4.7 & 5.2 \\
CAPEX (million $€$ ) & 22.3 & 25.2 & 28.3 & 31.3 \\
\hline
\end{tabular}

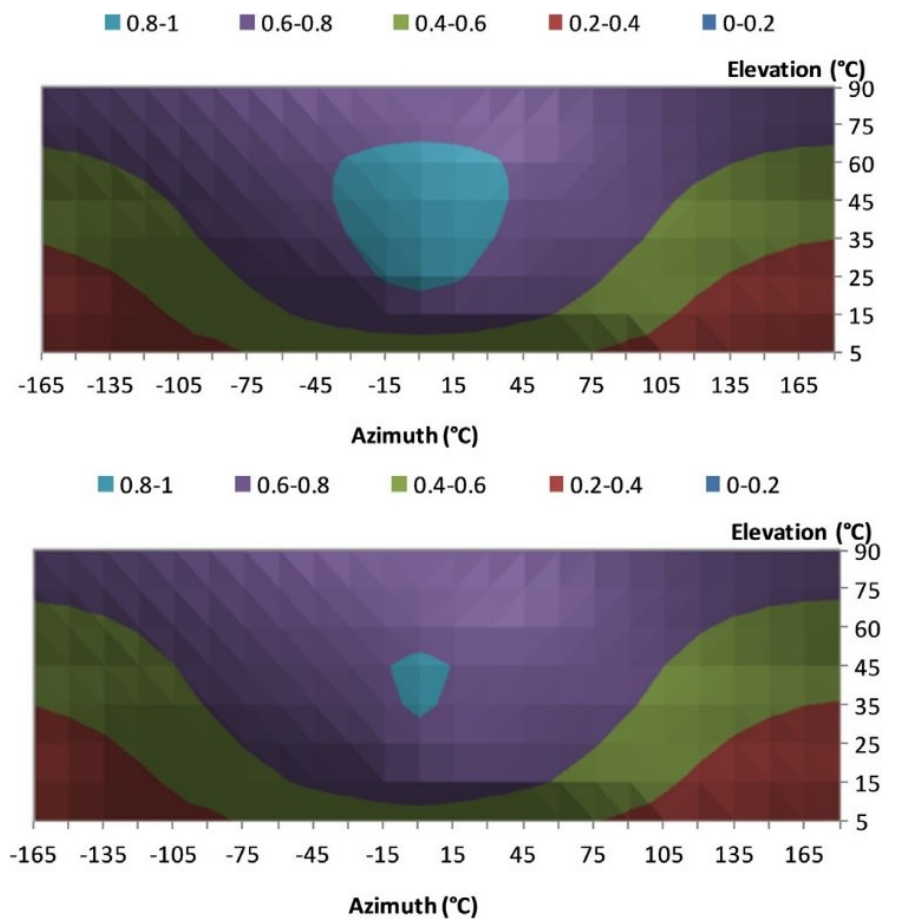

Fig. 7. Effect of solar multiple in the solar field performance for $S M=1.25$ (up) $S M=1.75$ (down).

The main costs associated with the power plant are the solar field, the receiver system, the power block and the storage device. Two variables that have a high influence in the size of these systems are the solar multiple and the storage capacity. Several combinations of storage capacities and solar multiples were considered, in order to optimize the power plant LEC, energy efficiency and energy dumping. A power plant with a solar multiple of 1 and absence of storage was simulated only for comparison purposes, because its operational viability is reduced. Power plants with solar multiples of 1.25, 1.5, 1.75 and 2.0 were considered, with different storage capacities from 1 to 7 equivalent operating hours, and four different control strategies, Fig. 8. 

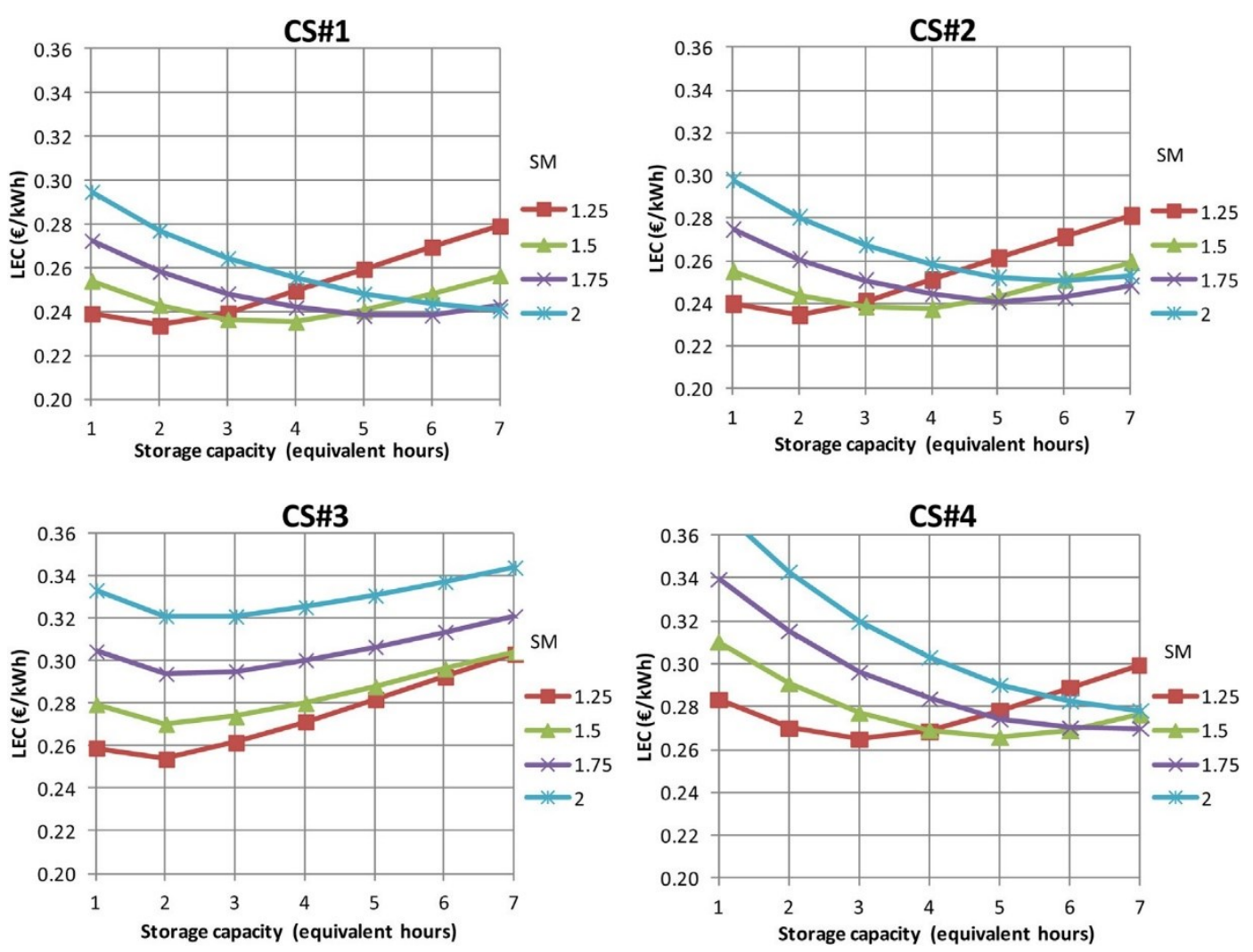

Fig. 8. Influence of solar multiple, storage capacity and control strategy (CS\#1 to CS\#4) on CRS LEC (lines are for readability).

The power plant configuration with best LEC $(0.234 € / \mathrm{kWh}, \mathrm{Fig} .8)$ is for $2 \mathrm{~h}$ storage and with a 1.25 solar multiple using CS\#1 (CRS_SM1.25_2S_CS\#1). There are some other power plant configurations using CS\#1, such as the CRS with 1.5 solar multiple and 3 or $4 \mathrm{~h}$ storage (CRS-1.5-3 or 4), that have a similar LEC ( $0.001 € / \mathrm{kWh}$ higher) but with higher CAPEX. For each solar multiple there is an optimal storage size and different configurations result in significant changes in the LEC, e.g. a 1.25 SM power plant with $7 \mathrm{~h}$ storage (CRS_SM1.25_7S_CS\#1) has a LEC almost 20\% higher than the optimal 1.25 SM power plant (CRS_SM1.25_2S_CS\#1). Similarly, for each storage capacity there is an optimal solar multiple, e.g. the $1.25 \mathrm{SM}$ power plant with $7 \mathrm{~h}$ storage (CRS_SM1.25_7S_CS\#1) has a 16\% higher LEC than the best $7 \mathrm{~h}$ storage power plant configuration (CRS_SM2.0_7S_CS\#1). These LEC variations are normally due to higher dumping or high periods of partial load operation. For improving the overall efficiency, instead of dumping energy this can be used for e.g. generating chemical products [20]. Fig. 9 summarizes the LECs of the best power plant configurations for each solar multiple, storage size and control strategies. 
a)

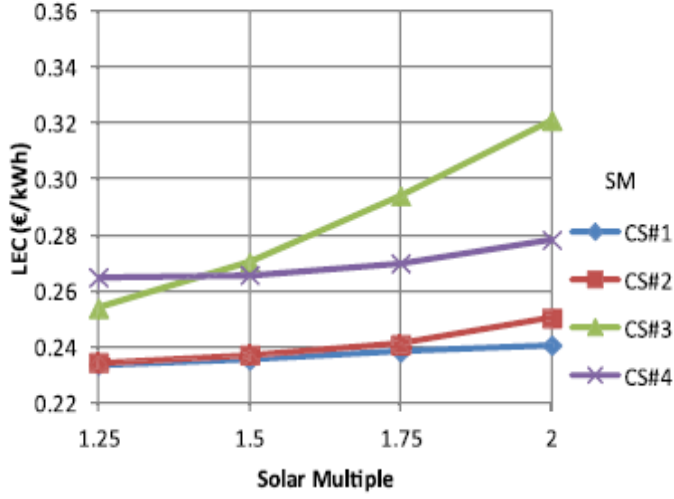

b)

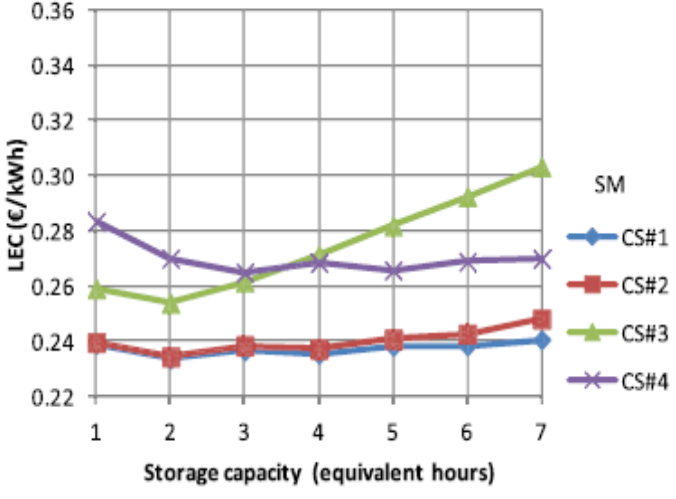

Fig. 9. a) Optimal power plant solar multiple configuration; b) and optimal storage capacity variations with control strategy (lines are for readability)

Fig. 9 demonstrates that the control strategy has a significant impact on the power plant LEC. If power plant operation is limited to 2 shifts (CS\#2), the partial load period and the operation and maintenance (O\&M) costs will decrease, but LEC will increase due to higher storage losses. This is clear for configurations with higher storage capacities and solar multiples, e.g. a power plant with 1.75 SM and $3 \mathrm{~h}$ storage using CS\#2 (CRS_SM1.75_3S_CS\#2) has a LEC of $0.241 € / \mathrm{kWh}$, while for the same power plant, but using CS\#1, the LEC is $0.238 € / \mathrm{kWh}$. If power plant operation is limited to 1 shift (CS\#3), the LEC increase is more notorious, especially for higher SM and storage capacities, because the CAPEX increases but the annual generated electricity remains identical (Fig. 9 e CS\#3). Also, since the power plant is located in an abundant solar radiation area, the LEC was further penalized for CS\#3 control strategy (this control strategy can be positive for lower DNI locations). For a complete economical analysis a detailed cash flow model was developed for several power plant configurations, Table 4.

Table 4. Power plant cash flow analysis and economic indicators

\begin{tabular}{|c|c|c|c|c|}
\hline Plant designation & Feed-in tariff $(\epsilon \mid \mathrm{kWh})$ & $\operatorname{IRR}(\%)$ & $\mathrm{NPV}$ (million €uro) ${ }^{\mathrm{d}}$ & Payback period (years) \\
\hline CRS_SM1.25_2S_CS\#1 & $0.273(24 \mathrm{~h})$ & 9.8 & 7.9 & 14 \\
\hline CRS_SM1.5_4S_CSH1 & $0.273(24 \mathrm{~h})$ & 9.6 & 9.4 & 15 \\
\hline CRS_SM1.75_55_CS\#1 & $0.273(24 \mathrm{~h})$ & 9.3 & 10.2 & 16 \\
\hline CRS_SM20_075_CSH1 & $0.273(24 \mathrm{~h})$ & 9.0 & 11.4 & 16 \\
\hline CRS_SM1.25_2S_CS\#2 & $0.273(24 \mathrm{~h})$ & 9.8 & 7.8 & 15 \\
\hline CRS_SM1.25_2S_CS\#2 & $\begin{array}{l}0.341 \text { (from } 9 \text { to } 22 \mathrm{~h} \text { ) } \\
0.164 \text { (remaining) }\end{array}$ & 17.0 & 16.9 & 7 \\
\hline CRS_SM1.25_2S_CS\#3 & $0.273(24 \mathrm{~h})$ & 7.6 & 4.9 & 20 \\
\hline CRS_SM1.25_3S_CS\#4 & $0.273(24 \mathrm{~h})$ & 6.1 & 3.1 & 23 \\
\hline CRS_SM1.25_3S_CS\#4 & $\begin{array}{l}0.341 \text { (from } 9 \text { to } 22 \mathrm{~h} \text { ) } \\
0.164 \text { (remaining) }\end{array}$ & 11.6 & 10.7 & 12 \\
\hline CRS_SM1.25_3S_CS\#4 & $\begin{array}{l}0.341 \text { (from } 9 \text { to } 13 \text { and } 18 \text { to } 22 \mathrm{~h} \text { ) } \\
0.164 \text { (remaining) }\end{array}$ & 8.2 & 6.0 & 18 \\
\hline
\end{tabular}

a Considering an average 4\% annual inflation. 
The investment in CRS power plants is attractive for the selected case (CRS_SM1.25_2S_CS\#1, Table 4), with high IRR (9.8\%) and moderate payback time (14 years), and good NPV for the power plant life cycle ( $€ 7.9$ million) even considering a conservative average inflation of $4 \%$ (well above the December 2012 inflation e 2.2\%, 2.3\% for the Euro Area and European Union, respectively [21]). Power plants with better NPV (up to $€ 11.4$ million) can be considered, but the CAPEX for these power plants is higher and the investment payback time is also higher. In a different perspective, if the objective is to generate electricity adjusted to the network demand (larger generation during demand peak hours), the power plant would only be viable if a bonus feed-in tariff is obtained (CRS_SM1.25_3S_CS\#4, Table 4). If the bonus tariff is obtained for the period between 9:00 to 13:00 and 18:00 to 22:00 h, the in-vestment IRR and NPV are below CS\#1; although, if the bonus tariff is obtained for the period from 9:00 to 22:00, the investment IRR and NPV are significantly higher than CS\#1. The selected 4 MWe CRS configuration for Faro conditions is then the CRS with $1.25 \mathrm{SM}$ and $2 \mathrm{~h}$ storage using CS\#1 (Figs. 8 and 9 and Table 4); the typical operational day is presented in Fig. 10.

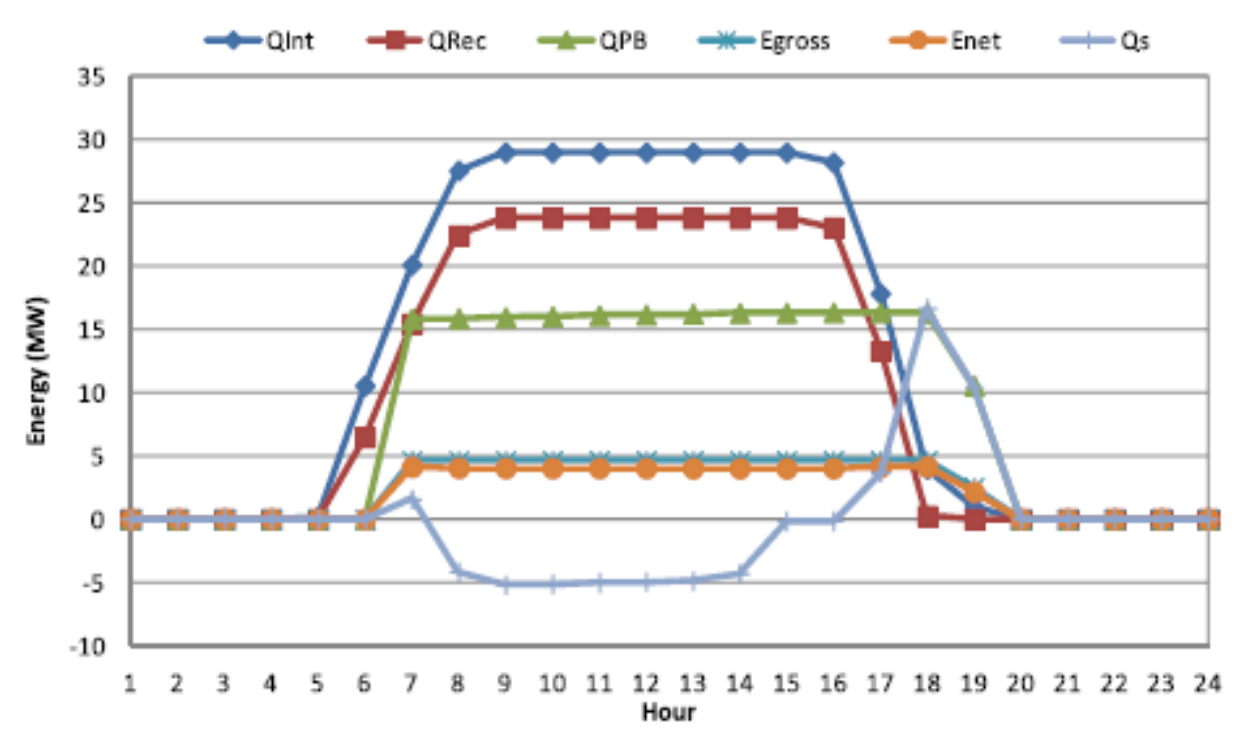

Fig. 10. Typical operational day for the $4 \mathrm{MWe}$ CRS with $1.25 \mathrm{SM}$ and $2 \mathrm{~h}$ storage fo CS\#1 (lines are for readability).

The power plant has an initial period when solar energy is available but the power plant is not generating electricity, followed by a period of partial load operation until the power plant begins operating at nominal load (at 8:00 e Fig. 10). After this period of time the power plant uses the excess energy to fill the storage (with $5 \mathrm{MWth}$ from 9:00 to 14:00). After this period the storage capacity is full and the excess energy is dumped. At the end of the day, available solar energy is reduced and the storage flow is reversed, extending power plant operation until 20:00 (Fig. 10). The $1.25 \mathrm{SM}$ and $2 \mathrm{~h}$ storage $4 \mathrm{MWe}$ CRS annual performance using CS\#1 (CRS_SM1.25_2S_CS\#1) is presented in Fig. 11. 


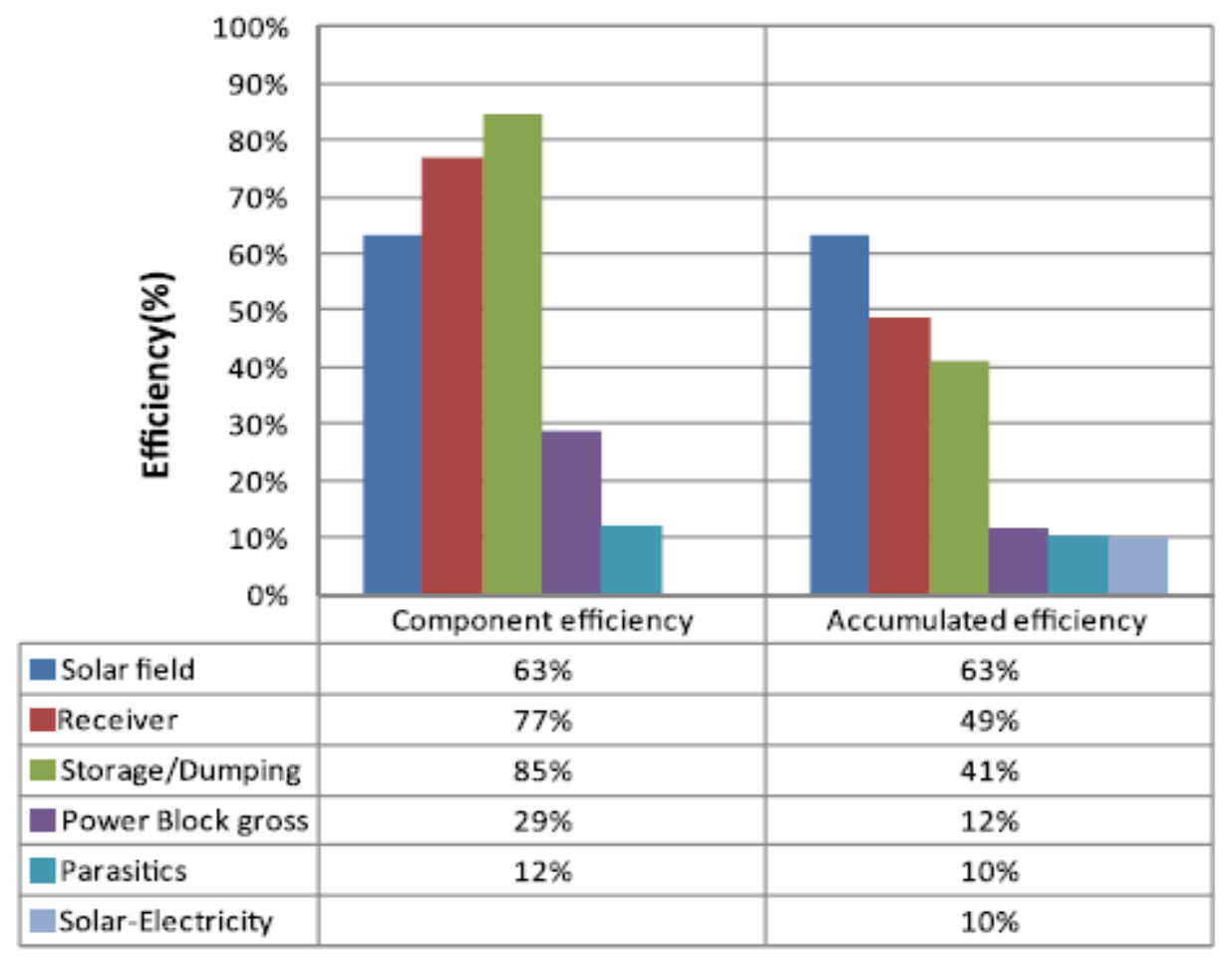

Fig. 11. Performance of the $4 \mathrm{MWe}$ CRS with $1.25 \mathrm{SM}$ and $2 \mathrm{~h}$ storage for CS\#1.

The solar field annual efficiency (63\% e Fig. 11) includes the heliostat stow positioning losses (caused e.g. by excessive wind) and the losses due to the solar DNI upper limit. The receiver annual efficiency is $77 \%$ e Fig. 11 e and the storage unit has an annual efficiency of $85 \%$ e Fig. 11. The storage unit efficiency includes the dumping losses when excess energy is available but the storage capacity is fulfilled. Up to the power block input the accumulated energy efficiency is $41 \%$ (Fig. 11). The component with lower efficiency is the power block (29\% gross e Fig. 11); its efficiency could be improved using a combined cycle (gas turbine plus steam tur-bine) but it would imply changing the receiver technology (e.g. pressurized air receiver) or to consider hybrid solutions. The scale-up of the power plant could also increase power block efficiency, as more efficient turbines can be used. The accumulated efficiency, solar to electricity, is $12 \%$ (Fig. 11). The parasitic loss, with the consumption of electric equipment, was $1.6 \mathrm{GWh}$ per year, with significant contributions of the air-cooled condenser and blowers. If these parasitic losses are taken into account, the overall solar to electricity efficiency is $10 \%$ (Fig. 11). Larger power plants can improve the solar to electricity efficiency up to $20 \%$ [22]. Also, the hybridization (e.g. with biomass) can significantly increase this value (up to $17 \%$ for $4 \mathrm{MWe}$ scale or $23 \%$ for $10 \mathrm{MWe}$ scale) [5].

4. Validity and sensibility analysis 
A sensitivity analysis is indispensable for LEC correct interpretation. The $4 \mathrm{MWe}$ power plant economical models (1.25 solar multiple and $2 \mathrm{~h}$ storage) include cost buffers and are based on budgets from several component manufacturers and on reliable references $[9,15,17]$. Nevertheless it is important to analyse the sensitivity of the LEC to possible cost increase of a single component or of several components. To analyse the sensitivity of the economical model, it was considered an additional $10 \%$ flat rate cost increase: solar field cost increases to $165 € / \mathrm{m} 2$; receiver cost increases to $131 € / \mathrm{kW}_{\text {th }}$; tower cost increases to $1,100,000 €$; the storage cost increases to $71 € / \mathrm{kWh}$; the power block cost increases to $737 € / \mathrm{kWe}$; and the land cost increases to $4.0 € / \mathrm{m}^{2}$, considering the reference costs of the main components (Table 1 ). The impact on the final LEC of each of these cost increments is illustrated in Fig. 12.

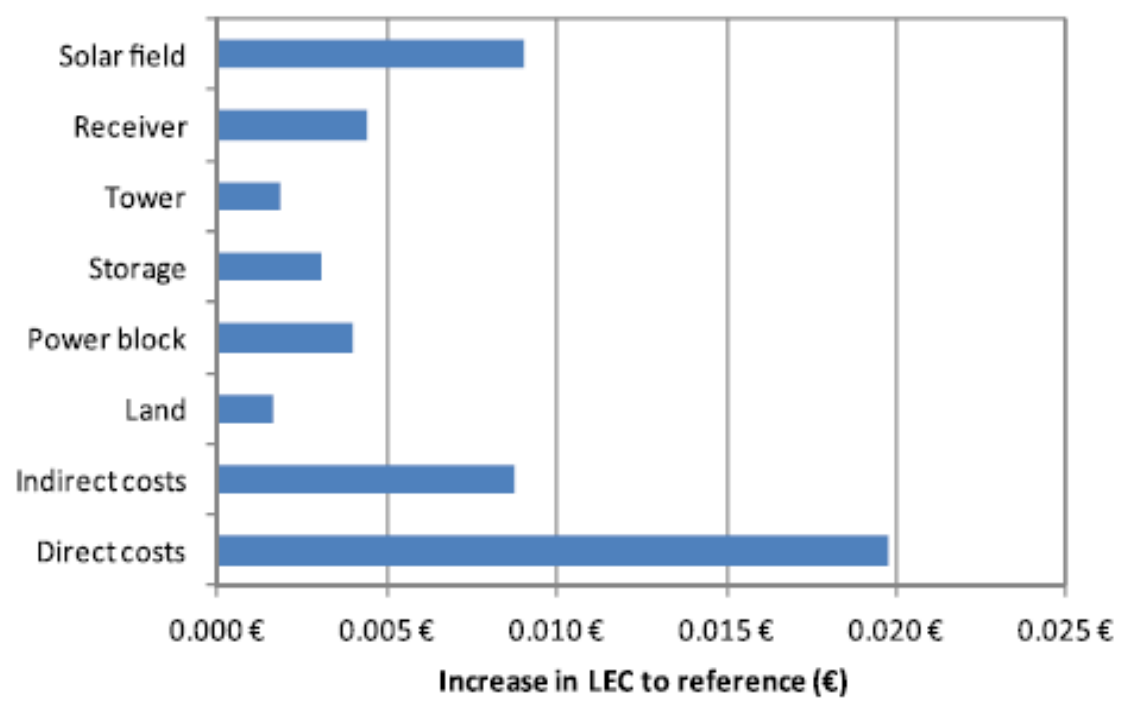

Fig. 12. Sensitivity impact of several factors in power plant LEC (compared to reference).

The sensitivity analysis can also be used to estimate the impact of several predictable technological and/or production improvements on the final LEC (e.g. component mass production or performance improvements). From this point of view, it was analysed the impact on LEC of: a) the application of thin film mirrors (higher reflectivity e 0.955 [23]); b) $20 \%$ reduction in heliostat costs to $120 € / \mathrm{m} 2$ [9] (dedicated heliostat production line); c) new storage materials (phase change materials or solid materials with ceramic saddles e $30 € / k W h_{\text {th }}$ [9]); d) increase in receiver performance by $10 \%$; and e) higher steam pressure power block. Some of these scenarios are based on products currently in the market (such as thin film mirrors and higher pressure power blocks), which were not considered in the base model due to a conservative approach used. Fig. 13 presents the impact of these new scenarios in the CRS levelized electricity cost. 


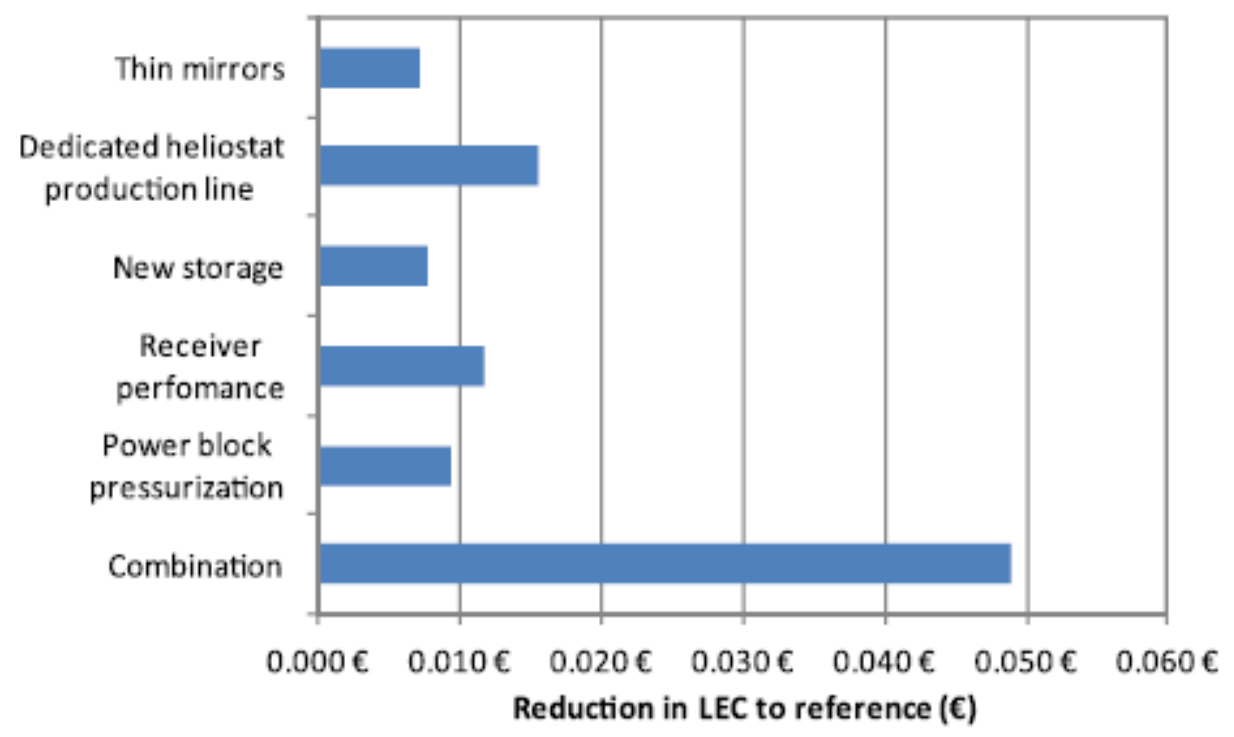

Fig. 13. Possible mid-term innovations impact in LEC (compared to reference)

The combination of all these improvements pushes CRS technology towards mid-term grid parity reducing the LEC to $0.185 € / \mathrm{kWh}$ (reduction of $0.049 € / \mathrm{kWh}, \mathrm{Fig} .13$ ). On the other hand, if a $10 \%$ direct cost overrun is considered, the LEC becomes $0.253 € / \mathrm{kWh}$ (Fig. 12), which is dangerously close to the feed-in tariff. The LEC methodology does not indicate the most profitable investment, which can be computed based on the power plant cash flows considering the variations on the power plant CAPEX but also on technical factors such as the generated electrical energy and power plant degradation and financial factors such as feed-in tariff, amortization period and local taxes. The cash flow sensitivity analysis to these technical and economical factors is presented in Table 5.

Table 5. Cash flow sensitivity analysis

\begin{tabular}{|c|c|c|c|c|}
\hline Type & Variation (to reference) & $\begin{array}{l}\text { New } \\
\text { IRR (\%) }\end{array}$ & $\begin{array}{l}\text { New NPV } \\
\text { (million } \\
\text { €uro)* }\end{array}$ & $\begin{array}{l}\text { New payback } \\
\text { period (years)* }\end{array}$ \\
\hline \multirow[t]{3}{*}{ Technical } & $\begin{array}{l}\text { Power degradation } \\
\text { ( } \pm 1 \% \text { point per year) }\end{array}$ & $7.6 / 11.9$ & $4.2 / 12.2$ & $19 / 12$ \\
\hline & CAPEX $( \pm 10 \%)$ & $7.7 / 12.2$ & $5.6 / 9.9$ & $19 / 11$ \\
\hline & Generated electricity $( \pm 10 \%)$ & $7.2 / 12.7$ & $4.5 / 11.5$ & $20 / 10$ \\
\hline \multirow[t]{7}{*}{ Financial } & Depreciation ( \pm 10 years) & $10.0 / 8.8$ & $7.6 / 6.9$ & $13 / 18$ \\
\hline & Loan time ( \pm 10 years) & $11.0 / 8.8$ & $7.1 / 8.9$ & $11 / 16$ \\
\hline & Insurance rate $( \pm 1 \%$ point $)$ & $8.7 / 11.1$ & $6.6 / 9.1$ & $17 / 12$ \\
\hline & Own capital (all/none) & $7.8 / 13.9$ & $10.4 / 6.4$ & $14 / 16$ \\
\hline & Debt interest ( $\pm 1 \%$ point) & $8.9 / 10.8$ & $6.9 / 8.8$ & $16 / 13$ \\
\hline & Profit taxes ( $\pm 2.5 \%$ point $)$ & $9.7 / 10.0$ & $7.6 / 8.2$ & $15 / 14$ \\
\hline & Inflation $( \pm 2 \% \text { point })^{* *}$ & $9.8 / 9.8$ & $4.2 / 13.3$ & $17 / 13$ \\
\hline
\end{tabular}

${ }^{*}-$ Considering an average $4 \%$ annual inflation, with exception of ${ }^{* *}$.

The cash flow analysis shown in Table 5 is sensitive to several parameters. This reinforces the necessity to perform a complete economical analysis, including a sensitivity analysis. The investment viability is highly influenced by deviations from the reference in the CAPEX, generated electricity and power plant degradation. 
The financial factors also have considerable impact on the power plant economical viability. Most of the financial factors are defined or influenced by the policy makers. One of the major concerns from the power plant operators and investors is the stability of the national and international financial factors such as taxes, debt interests, inflation, feed-in tariffs, so a CRS power plant long-term investment has a positive return. This is reinforced by the results given in Table 5; a worst than reference scenario can decrease the NPV by almost $€ 4$ million or increase the payback period by 2-3 years; however, a more positive scenario e.g. if the actual annual average inflation is maintained at $2 \%$ ( $2 \%$ lower than reference), the power plant investment can have very positive contours, with NPV close to $€ 13$ million and an own capital payback of 13 years. The capital payback can be shortened up to 11 years, with an IRR of $11 \%$, if the loan is extended to 30 years, but the NPV becomes $€ 0.8$ million smaller (Table 5 ).

\section{Conclusions}

Within the Portuguese reality, atmospheric air volumetric central receiver systems have good performances and economical indicators. For Faro conditions, the selected $4 \mathrm{MWe}$ power plant configuration uses a 1.25 solar multiple, a $2 \mathrm{~h}$ storage and control strategy \#1 (CS\#1). The respective power plant LEC is $0.234 € / \mathrm{kWh}$ with a CAPEX of $€ 22.3$ million. If $30 \%$ own capital, and a 20 year loan with an interest rate of $8 \%$ financing structure is selected, with $1 \%$ of power plant degradation, a 1\% annual insurance rate, a linear amortization for 20 years, feed-in tariff of $0.273 € / \mathrm{kWh}$ and current national profit taxes, the investment IRR is $9.8 \%$, with a payback time of 14 years and an NPV of $€ 7.9$ million (considering an average annual inflation of $4 \%$ ).

The solar multiple and storage capacity have a significant impact on power plant LEC and their optimization and control strategy can save significant capital for the investors. CS\#1 presents better economical results compared to CS\#2 and CS\#3, due to higher annual electricity generation, despite higher personnel and maintenance costs. This is notorious for larger solar multiple and storage capacity power plants (base load power), with higher investment, but no return on the annual generated electricity. If the objective is to use CSP for power on demand, adjusting the supply to the demand peaks, CS\#4 can be an interesting solution but only if a bonus tariff is considered for these periods.

The sensitivity analysis indicates that both LEC and power plant cash flow are influenced by variations in CAPEX, generated electricity, financing strategy and economic indicators. In the case of better than reference economic indicators (annual average inflation of $2 \%$ instead of $4 \%)$, the power plant investment has very positive contours, with NPV close to 13 million €uro and a payback period of 13 years. Also, if some commercial or under development innovations are introduced in the power plant, LEC can be reduced close to grid parity $(0.185 € / \mathrm{kWh})$.

\section{References}

[1] Despacho n. 0 18838/2009, Diário da República n. 0 157, 2a Série de 14 de Agosto de 2009.

[2] Romero M, Zarza E. Handbook of energy efficiency and renewal energy, chapter 21: concentrating solar thermal power. CRC Press; 2007.

[3] Project information e solar thermal investigation plant in Jülich brochure. 
Kraftanlagen München GmbH; 2010.

[4] REN. Caracterização da rede nacional de transporte para efeitos de acesso à rede em 31 de dezembro de 2011; 2011.

[5] Coelho B, Schwarzbözl P, Oliveira AC, Mendes A. Biomass and central receiver system (CRS) hybridization: volumetric air CRS and integration of a biomass waste direct burning boiler on steam cycle. Sol Energy 2012;86(10):2912e22.

[6] Schillings C, Trieb F. MED-CSP study, concentrating solar power for the Mediterranean region. DLR; 2005.

[7] Gila A, Medranoa M, Martorella I, Lázarob A, Doladob P, Zalbab B, et al. State of the art on high temperature thermal energy storage for power generation. Part 1dconcepts, materials and modellization. Renew Sustain Energy Rev 2010;14:31e55.

[8] Zunft S, Hänel M, Krüger M, Dreissigacker V, Göhring F, Wahl E, et al. Jülich solar power tower e experimental evaluation of the storage subsystem and performance calculation. J Sol Energy Eng 2011;133:1e5.

[9] Pitz-Paal R, Dersch J, Milow B. ECOSTAR roadmap document. DLR; 2005.

[10] Klein A, Pfluger B, Held A, Ragwitz M, Resch G, Faber T, et al. Evaluation of different feed-in tariff design options. 3rd ed. Fraunhofer ISI and EEG; 2010.

[11] Stine W, Harriganm R. Solar energy fundamentals and design. John Wiley \& Sons, Inc.; 1985.

[12] Schwarzbözl P. The user's guide to HFLCAL. Software release visual HFLCAL VH12; 2009.

[13] EBSILON ${ }^{\circledR}$ Professional. www.steag-systemtechnologies.com/ [accessed 23.01.12].

[14] Coelho B, Varga S, Oliveira AC, Mendes A. Atmospheric air volumetric central receiver system power plant optimization: impact of power block, design DNI and receiver flux. Manuscript Number RENE-S-12-02178. Renew Energy.

[15] EFACEC Engineering Portugal. Personal communication, June 2011.

[16] Mancini T. Catalog of solar heliostats. SolarPaces technical report; 2000.

[17] Siemens Portugal. Personal communication, June 2011.

[18] Seider W, Seader J, Lewin D. Product and process design principles: synthesis, analysis, and evaluation. 2nd ed. Wiley; 2004.

[19] Peters M, Timmerhaus K, West R. Plant design and economics for chemical engineers. 5th ed. McGraw Hill; 2003.

[20] Coelho B, Oliveira AC, Mendes A. Concentrated solar power for renewable electricity and hydrogen production e a review. Energy Environ Sci 2010;3: $1398 \mathrm{e} 405$.

[21] http://epp.eurostat.ec.europa.eu/inflation_dashboard [accessed on 03.02.12].

[22] Sargent and Lundy LLC Consulting Group. Assessment of parabolic trough and power tower solar technology cost and performance forecasts. NREL/SR-55034440; 2003.

[23] http://www.flabegsolar.com/index.php?id $1 / 4144 \& L=1$ [accessed on 13.07.11]. 